\title{
PEKANBARU SCIENCE AND TECHNOLOGY CENTER DENGAN PENDEKATAN ARSITEKTUR FUTURISTIK BERBASIS TEKNOLOGI TINGGI
}

\author{
Oleh: \\ Muhamat Fauzi, Titin Sundari, Boby Samra \\ Program Studi Arsitektur, Fakultas Teknik, Universitas lancang Kuning \\ Jl. Yos Sudarso km. 08 Rumbai, Pekanbaru, Telp. (0761) 52324 \\ muhammadfauzi011@yahoo.co.id, titin@unilak.ac.id, boby@unilak.ac.id
}

\begin{abstract}
ABSTRAK
Kota Pekanbaru merupakan ibu kota dan kota terbesar di Provinsi Riau, Indonesia. Kota Pekanbaru terletak dibagian tengah pulau sumatera, letaknya yang sentris menjadikannya keuntungan tersendiri dalam beberapa hal, salah satunya yaitu terkait sektor pendidikan dalam bidang sains dan teknologi. Terkait hal tersebut juga merujuk terhadap kurangnya tempat rekreasi dan pemerataan kualitas pendidikan, maka dari itu sesuai dengan target visi dan misi Kota Pekanbaru tahun 2021 salah satunya pada sektor pendidikan, layak mendapatkan perhatian lebih. Dengan adanya fasilitas wisata berbasis edukasi, diharapkan mampu memadukan kegiatan edukasi yang serasi antara konsep pendidikan dan konsep rekreasi, sehingga dapat melahirkan sumber daya manusia yang berkualitas dan mampu bersaing dikancah nasional maupun internasional. Konsep futuristik berbasis teknologi tinggi diterapkan dalam perancangan karena sesuai dengan fungsi dan kegiatannya. Metode perancangan pada Pekanbaru Science And Technology Center ada beberapa jenis yaitu analisis manusia, lingkungan, bangunan, serta analisis bangunan futuristik berbasis teknologi tinggi. Hasil dari perancangan berupa kebutuhan ruang, zoning tapak, gubahan massa bangunan, dan gambar pra-rancangan fisik.
\end{abstract}

Kata kunci: Sains dan Teknologi, Arsitektur Futuristik, Kota Pekanbaru

\begin{abstract}
Pekanbaru City is the capital and largest city in Riau Province, Indonesia. The city of Pekanbaru is located in the central part of the island of Sumatra, its centric location makes it a distinct advantage in several ways, one of which is related to the education sector in the fields of science and technology. Related to this also refers to the lack of recreational areas and equal distribution of quality of education, therefore according to the target of the vision and mission of the city of Pekanbaru in 2021 one of which is in the education sector, deserves more attention. With the education-based tourism facilities, it is expected to be able to integrate educational activities that are harmonious between the concepts of education and the concept of recreation, so that it can produce quality human resources and be able to compete in national and international levels. The futuristic concept based on high technology is applied in the design because it is in accordance with its functions and activities. There are several types of design methods at the Pekanbaru Science And Technology Center, namely human, environmental, building analysis, and futuristic building analysis based on high technology. The results of the design in the form of space requirements, site zoning, building mass composition, and physical design drawings.
\end{abstract}

Keywords: Science And Technology, Futuristic Architecture, Pekanbaru City 


\section{PENDAHULUAN}

Pekanbaru merupakan ibu kota dan kota terbesar di Provinsi Riau, Indonesia. Letaknya yang strategis dan posisinya yang sentris tepat berada ditengah pulau sumatera, menjadikannya keuntungan tersendiri, baik dari segi jangkauan wilayah, transportasi, dan potensi lainnya yang dapat berkembang dengan pesat, apabila dikembangkan dengan baik guna mencapai target visi dan misi, salah satunya yaitu pada sektor pendidikan.

Dengan mewujudkan visi dan misi Kota Pekanbaru tahun 2021, diharapkan pada sektor pendidikan dapat dibenahi dengan dihadirkannya fasilitas penunjang pendidikan non formal, salah satunya pada bidang sains dan teknologi, guna membantu masyarakat dalam mengetahui inovasi dan teknologi terdahulu dan masa kini, serta memberikan pendidikan ekstra khususnya mulai dari pra-sekolah, tingkat sd, smp, sma dan bangku perkuliahan dapat menggunakan fasilitas tersebut.

Begitu pentingnya peranan sains dan teknologi sehingga keberadaannya mutlak diperlukan dalam rangka pergaulan ditingkat regional, nasional, maupun internasional. Berbagai aspek yang ada pada sains dan teknologi dapat memberikan nilai positif bagi kepentingan yang lebih luas sebagai lembaga pendidikan non formal yang sekaligus sebagai objek pariwisata (Rekreasi).

Pekanbaru Science And Technology Center ini di rencanakan sebagai fasilitas rekreasi wisata berbasis (pendidikan), dimana para pengunjung tidak hanya menghabiskan waktu untuk mempelajari sains dan teknologi, tetapi juga ikut merasakan nuansa rekreasi melalui penerapan konsep pembelajaran yang edukatif, rekreatif, dan komunikatif (Belajar sambil bermain) tanpa ada batasan usia.

Dikarenakan letaknya yang strategis dan bukan tidak mungkin status nya dapat menjadi sains dan teknologi nasional atau bahkan internasional, maka dari itu pengembangan pra-rancangan Pekanbaru Science And Technology Center dirancang dengan pengimplementasian desain futuristik berbasis teknologi tinggi agar dapat menjadi solusi gambaran masa depan serta sesuai dengan fungsi didalamnya yang menyajikan ilmu pengetahuan dan teknologi.

\section{METODE PERANCANGAN}

Metode perancangan yang digunakan untuk mendapatkan data-data yang terkait Pekanbaru Science And Technology Center adalah dengan metode analisis aspek manusia, analisis aspek lingkungan, dan analisis aspek bangunan yang diperoleh dari studi literatur, studi empiris, dan studi lapangan. Data yang dianalisis tersebut nantinya berupa konsep yang diterapkan dalam prarancangan Pekanbaru Science And Technology Center. a. Analisis Aspek Manusia

Analisis aspek manusia memiliki tujuan untuk mengelompokkan pengguna bangunan dan jenis aktifitas, kebutuhan besaran ruang yang mewadahi manusia serta memenuhi kriteria pengguna pada Pekanbaru Science And Technology Center.

b. Analisis Aspek Lingkungan

Tujuan analisis aspek lingkungan untuk menentukan lokasi perancangan Pekanbaru Science And Technology Center yang berada di Kota Pekanbaru, berdasarkan beberapa kriteria dan penilaian sehingga memenuhi syarat peruntukan lahan dan perencanaan.

c. Analisis Aspek Bangunan

Analisis aspek bangunan bertujuan untuk mengetahui korelasi antara topik dan tema yang diaplikasikan kedalam perancangan, bentuk dasar bangunan, gubahan massa bangunan, ruang dalam, sistem sirkulasi dan parkir, struktur, utilitas, apakah sudah sesuai dengan yang direncanakan sesuai topik dan tema yang dipilih.

\section{HASIL DAN PEMBAHASAN}

\section{Tinjauan Teoritis}

Pengertian Science And Technology Center merupakan sebuah fasilitas pusat pengetahuan/ keilmuan yang memiliki beberapa cabang bidang ilmu pengetahuan murni (Sains) dan ilmu pengetahuan terapan (Teknologi) yang mewadahi pengguna untuk memenuhi rasa keingintahuannya dalam mempelajari Sains dan Teknologi

\section{Klasifikasi Science And Technology Center}

Pada umumnya Science And Technology Center merupakan wadah atau sarana rekreasi berbasis edukasi. Dimana didalamnya terdapat berbagai macam alat peraga yang dapat disentuh, pajangan koleksi, dan berbagai inovasi hingga terkini.

Menurut (ICOM, 1974) Science And Technology Center pada dasarnya merupakan suatu lembaga yang bergerak dibidang pendidikan khususnya sebagai sarana pendidikan non formal. Secara umum Science And Technology Center dapat dikatakan sejenis dengan museum seperti yang tercantum pada International Council of Museum (ICOM) pada poin kelima disebutkan "Science Centers and Planetariums" termasuk kedalam klasifikasi/ jenis Science Museum.

Namun dalam beberapa hal Science And Technology Center dan museum memiliki perbedaan yang jelas. Yaitu dalam hal sifat peraganya. Pada Science And Technology Center sifat peragaannya bukan hanya melihat obyek (Object Oriented), melainkan melibatkan pengamat untuk berperan (Experience Oriented).

Konsep pendekatannya adalah proses belajar melalui cara mencoba/ bereksperimen, berperan secara 
aktif dengan cara menyentuh, memainkan dan menekan tombol dengan mengandalkan mekanikal, elektrikal, audio visual dan teknik-teknik lain, berbeda dengan museum yang mengkomunikasikan warisan budaya melalui penggunaan obyek berupa karya seni atau benda historis yang umumnya indah, unik dan mahal.

Science And Technology Center memungkinkan pengunjung tanpa latar belakang pendidikan dan minat tertentu serta dari berbagai usia dan kalangan dapat memahami segala apresiasi yang disajikan secara atraktif.

Menurut (ICOM, 1974) Science And Technology Center terdiri 3 kategori yaitu (Yang digunakan ialah Educationally Oriented Center):

a. Pusat Sains Kompleks (Comprehensive Centers)

1) Pusat sains yang berorientasi ke bidang industri (industrially oriented centers).

2) Pusat sains yang berorientasi ke bidang pendidikan (Educationally Oriented Center).

b. Pusat Sains Khusus (Specialized Centers) Merupakan pusat sains dengan aspek yang lebih sempit dan khusus yang terbagi dalam beberapa kategori, yaitu :

1) Pusat sains kesehatan (Healty Centers)

2) Pusat sains energi (Energy Centers)

3) Pusat sains transportasi (Transportation Centers).

4) Pusat sains yang berkaitan dengan angkasa luar (Space Centers).

5) Pusat sains alami (Nature Centers)

c. Pusat Sains Terbatas (Limited Centers)

Tugas dan fungsi Science And Technology Center pada dasarnyna sebagai berikut:

1) Pusat Dokumentasi dan Penelitian Ilmiah

2) Pusat Penyaluran ilmu untuk umum

3) Pusat penikmatan karya ilmiah

4) Obyek Wisata

5) Media pembinaan pendidikan dan ilmu pengetahuan

6) Cermin sejarah manusia, alam dan kebudayaan

7) Sarana untuk bertakwa dan bersyukur kepada Tuhan

\section{Arsitektur Futuristik}

Futuristik mempunyai arti yang bersifat mengarah atau menuju masa depan. Citra futuristik pada bangunan berarti citra yang mengesankan bahwa bagunan itu berorientasi ke masa depan atau citra bahwa bangunan itu selalu mengikuti perkembangan jaman yang ditunjukkan melalui ekspresi bangunan.

Fleksibilitas dan kapabilitas bangunan adalah salah satu aspek futuristik bangunan. Fleksibilitas dan kapabilitas sendiri adalah kemampuan bangunan untuk melayani dan mengikuti perkembangan tuntutan dan persyaratan pada bangunan itu sendiri. Sedangkan kemampuan untuk melayani dan mengikuti perkembangan jaman hanya bisa diwujudkan atau diimplementasikan dalam penampilan dan ungkapan fisik bangunan.

Menurut Haines (1950) dan Chiara dkk (1980) dalam Kusumawati (2008) kriteria diatas adalah bangunan itu dapat mengikuti dan menampung tuntutan kegiatan yang senantiasa berkembang. Bangunan tersebut senantiasa dapat melayani perubahan perwadahan kegiatan, disini perlu dipikirkan kelengkapan yang menunjang proses berlangsungnya kegiatan. Adanya kemungkinan penambahan ataupun perubahan pada bangunan tanpa mengganggu bangunan yang ada dengan jalan perencanaan yang matang.

Futuristik sebagai core value atau nilai-nilai dasar mengandung nilai-nilai yaitu dinamis, estetis dan inovatif terutama dari segi teknologi yang dipakai (dinamis, canggih dan ramah lingkungan) dengan mengadopsi bentuk-bentuk bebas yang tidak terikat oleh bentuk-bentuk tertentu.

Dalam futuristik juga perlu dipikirkan mengenai estimasi atau perkiraan pengenalan akan bangunan futuristik dapat dilakukan dengan pendekatan yang sesuai dengan perkembangan kebutuhan manusia. Salah satu cara untuk memprediksi tentang arsitektur masa depan adalah dengan mengikuti perkembangan arsitektur berteknologi tinggi pada masanya yang berkembang setelah tahun 1960-an dengan ciri-ciri sebagai berikut:

a. Kebenaran struktur.

b. Bentuk bebas cenderung ke bentuk yang berhubungan dengan alam.

c. Proyeksi yang berupa hasil perhitungan menghasilkan sesuatu yang lebih baik.

d. Pendekatan dengan penemuan hal-hal yang baru.

e. Futuristik adalah lambang perubahan, dinamis dan menembus ruang tidak nampak.

Dalam ilmu arsitektur, terminologi arsitektur futuristik masih rancu atau belum dapat digolongkan ke dalam kriteria arsitektur modern, late modern maupun post modern. late modern dapat terlihat secara visual dari bangunan dengan memanfaatkan bentuk, penggunaan material, warna, struktur dan teknologi yang membuat late modern berkembang juga menjadi beberapa aliran seperti Platism, Suprematism, Hightech dan lain-lain (Permana, 2009).

Futuristik/ futurism merupakan suatu paham kebebasan dalam mengungkapkan atau mengekspresikan ide atau gagasan ke dalam suatu bentuk tampilan yang tidak biasa, kreatif, dan inovatif. Hasil dari futuristik ini adalah sesuatu yang dinamis, selalu berubah-ubah sesuai keinginan dan zamannya. Penerapan futuristik ini hanya terlihat pada penampilan atau tampaknya dengan tetap memperhatikan dan memperhitungkan fungsi dari objeknya (Tiffany, 2012). 
Futuristik sejalan dengan perkembangan teknologi dimana dengan semakin majunya teknologi yang diciptakan manusia maka keberadaan futuristik itu juga akan semakin berkembang.

\section{Karakteristik Bangunan Futuristik}

Menurut (Antonia Sant'Elia, 2009) pada bukunya "Futurism An Anthology" Karakteristik arsitektur futuristik adalah :

a. Arsitektur futuristik memerlukan perhitungan matang, keberanian/tekad yang kuat untuk mencapai nilai keelastisan yang maksimum.

b. Arsitektur futuristik juga memperhatikan seni ekspresi pada tampilannya.

c. Arsitektur futuristik lebih memanfaatkan tipe garisgaris miring dan elips untuk menciptakan unsur dinamis.

d. Arsitektur futuristik tidak menggunakan seni ornamentasi didalam bangunan untuk mengekspresikan suatu bentuk yang dikehendaki.

e. Arsitektur futuristik merupakan kunci perubahan untuk menemukan inspirasi yang baru.

f. Arsitektur futuristik dipahami sebagai upaya yang diimplementasikan dengan kebebasan dan keberanian menyelaraskan manusia dan lingkungannya.

\section{Data Tapak}

Secara regional lokasi tapak Pekanbaru Science And Technology Center berada di Kota Pekanbaru dikelilingi beberapa kota kecil lainnya yang ada di Provinsi Riau dapat dengan mudah diakses dengan berbagai moda transportasi yang ada saat ini.

Lokasi prarancangan terletak Jl. Tuanku Tambusai dengan luas $38.050 \mathrm{~m}^{2}$ (3.8 Ha/ Hektar) berada di kecamatan Payung Sekaki, Kelurahan Air Hitam, Kota Pekanbaru, Provinsi Riau.

Lokasi tersebut berada di bagian wilayah perencanaan lima, dekat dengan berbagai fasilitas umum dan fasilitas lainnya, sehingga sangat mendukung dan berpotensi untuk mewadahi kegiatan edukasi dan rekreasi sesuai gambar 1 dibawah ini:

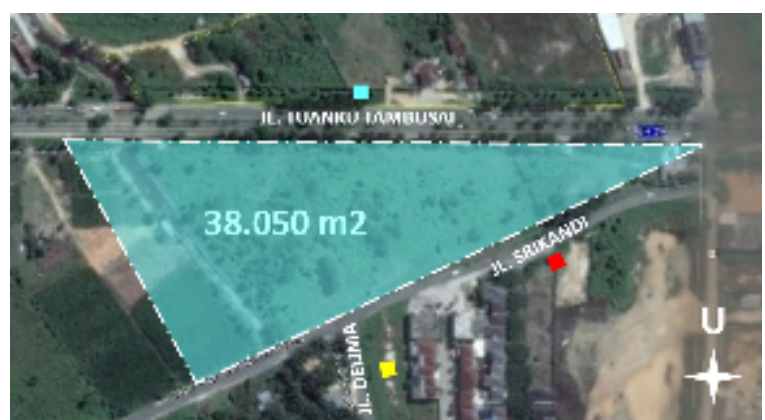

L I. TUANKL TAMARKAI E JL. SRIKANDI IJL DEUMAA

Gambar 1. Lokasi Tapak

(Sumber: Analisis Penulis) a. Batas-Batas Dimensi tapak

Berikut detail penjelasan batasan pada tapak dapat dilihat pada gambar 2 sebagai berikut:

1) Tapak sebelah utara berbatasan dengan jalan utama Jl. Tuanku Tambusai dan lahan kosong.

2) Tapak sebelah selatan berbatasan dengan lahan kosong dan perumahan.

3) Tapak sebelah barat berbatasan dengan anak sungai dan lahan kosong.

4) Batas sebelah timur berbatasan dengan lahan kosong dan toko retail.

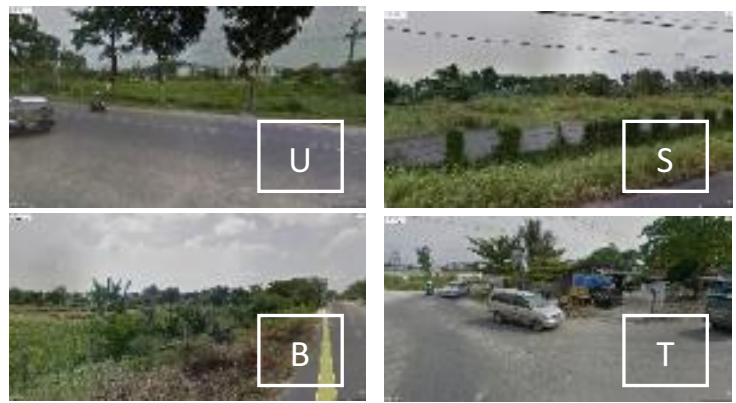

Gambar 2. Batas-batas Dimensi Tapak

(Sumber: Analisis Penulis)

b. Aksessibilitas Tapak

Dapat dilihat pada gambar 3 tapak dapat diakses dari arah Tugu songket melayu/ Terminal payung sekaki (1), Dari arah mall SKA Jl. Tuanku tambusai (2), dan Jl. Srikandi (3).

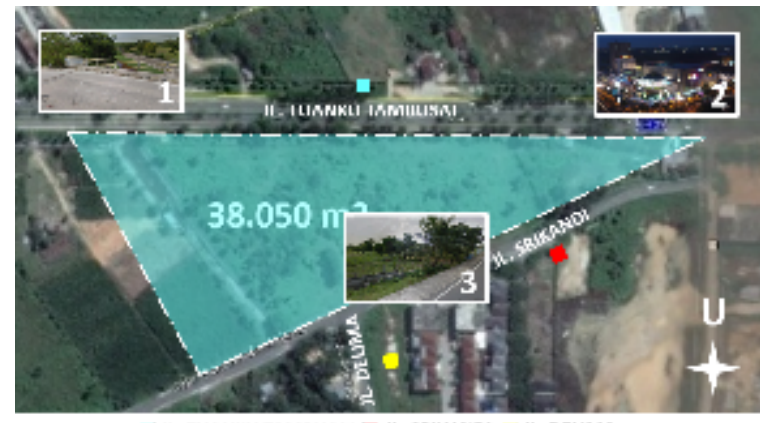

」II. TLANKLL TAMAILISAI E JL. SAIKANDI IIL DELMA

Gambar 3. Aksesibilitas Tapak

(Sumber: Analisis Penulis)

c. Penampang Tapak

Berikut detail penampang tapak seperti pada gambar 4 dibawah ini :

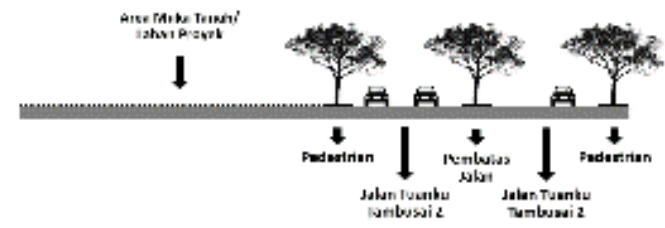

Gambar 4. Penampang Tapak

(Sumber: Analisis Penulis) 
d. Orientasi Tapak

Pada gambar 5 dibawah ini matahari pagi berada dibagian timur tepat dibagian teman rekreatif, dan berakhir dibarat pada bagian taman edukatif.

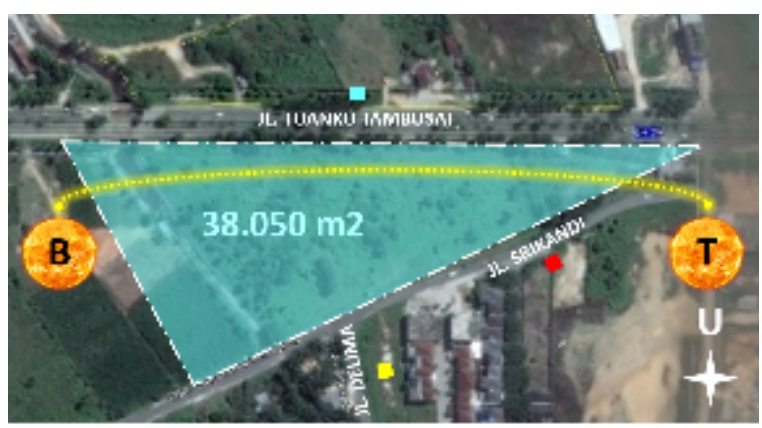

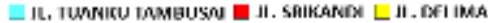

Gambar 5. Orientasi Tapak

(Sumber: Analisis Penulis)

\section{Analisis Science And Technology Center}

Dalam prarancangan Pekanbaru Science And Technology Center dianalisis dengan beberapa metode seperti analisis manusia, aspek lingkungan, aspek bangunan, serta aspek topik dan tema.

\section{Analisis Aspek Manusia}

Faktor manusia merupakan aspek yang berperan penting, karena didalamnya terdapat aktifitas yang membutuhkan ruang dan fasilitas. Terdapat beberapa aktifitas pengguna didalam bangunan Pekanbaru Science And Technology Center, antara lain :

a. Pengunjung

Pengunjung merupakan bagian penting dalam sebuah perencanaan, tanpa pengunjung, sebuah fasilitas tidak akan berjalan dengan baik.

b. Pengelola

Pengelola merupakan badan organisasi yang terbagi dalam beberapa divisi dan sub divisi dan mengelola fasilitas secara menyeluruh.

c. Penyewa

Penyewa mengelola jasa/ produk yang mereka sediakan sebagai bagian dari rekan bisnis.

Analisis Kebutuhan Ruang:

Tabel 1. Rekapitulasi

\begin{tabular}{|c|l|l|c|}
\hline No & \multicolumn{1}{|c|}{ Kelompok Kegiatan } & \multicolumn{1}{|c|}{ Kelompok Ruang } & Luasan $\left(\mathbf{m}^{\mathbf{2}}\right)$ \\
\hline 1 & Penerima & Penerima & 3348,25 \\
\hline \multirow{2}{*}{2} & \multirow{2}{*}{ Belajar } & Perpustakaan & 262,2 \\
\cline { 3 - 4 } & & Area science center & 1811,3 \\
\hline \multirow{2}{*}{3} & \multirow{2}{*}{ Bermain dan Rekreasi } & Tempat Bermain & 2002,6 \\
\cline { 3 - 5 } & & Taman & 2000 \\
\hline 4 & Pendukung & Pendukung & 1642 \\
\hline \multirow{2}{*}{5} & \multirow{2}{*}{ Pengelola } & Pengelola & 1128,6 \\
\cline { 3 - 5 } & & Servis & 499,65 \\
\hline
\end{tabular}

\section{Analisis Aspek Lingkungan}

Analisis terhadap aspek lingkungan terdiri dari beberapa penilaian kriteria, sebagai berikut :

a. Penilaian berdasarkan letak lokasi tapak, berdasarkan wilayah perencanaan kota, terletak di wilayah pengembangan lima (Pendidikan dan Rekreasi) sangat ideal.

b. Berdasarkan alternatif lokasi yang ada, lokasi tapak ini memiliki potensi dan keuntungan tersendiri dibandingkan alternatif lain.

c. Potensi yang ada pada lokasi tapak ini sangat baik.

d. Regulasi terkait perencaan juga sangat diperhitungkan dengan baik, sehingga perencanaan sesuai dengan target.

e. Orientasi bangunan mengikuti bentuk tapak, dengan mengikuti arah matahari terbit sebagai bagian awal, dan arah matahari terbenam sebagai bagian dari akhir kegiatan yang akan berlangsung pada perencanaan ini.

f. Tingkat kebisingan tidak terlalu signifikan, dan dapat dipecahkan dengan beberapa solusi dan alternatif.

g. Pandangan/ view pada lokasi tapak sangat baik, dapat dilihat dari berbagai sudut, baik dari dalam, maupun dari luar.

h. Aksessibilitas pada tapak sangat mendukung, tersedia banyak fasilitas, sangat mudah dijangkau, dan juga memperhatikan para penyandang disabilitas.

i. Zoning tapak terdiri dari tiga bagian, bangunan utama, parkir outdoor, dan area vegetasi/ open space

\section{Analisis Aspek Bangunan}

Analisis aspek bangunan terdiri dari beberapa pembahasan sebagai berikut :

a. Analisis topik dan tema

Topik yang diangkat ialah pendekatan "Arsitektur Futuristik", banyak pertimbangan dalam menentukan topik terkait prarancangan Pekanbaru Science And Technology Center. Penerapan futuristik pada bangunan melalui pola bentuk yang dinamis sehingga tercipta unsur estetis yang inovatif dan atraktif. Juga pada bagian ruang dalam, kesan futuristik juga disematkan dalam media alat peraga, dan lainnya.

Sejalan dengan topik, tema yang diangkat adalah "Pendekatan Rancangan Berbasis Teknologi Tinggi", beberapa aplikasi yang diterapkan seperti BAS (Building Automation System), selain untuk kemudahan dan tingkat keandalan yang tinggi, juga memiliki keuntungan dan dampak yang positif terhadap penggunaannya yang menggambarkan kecanggihan masa depan. 
b. Analisis bentuk dasar bangunan

Bentuk dasar bangunan mengikuti pola tapak yang berbentuk segitiga, dengan mengikuti latar belakang iptek, pesawat menjadi salah satu alternatif kuat untuk diimplementasikan sebagai bagian dari penghargaan salah satunya kepada Presiden RI ketiga "Prof. BJ Habibie" sebagai pelopor yang luar biasa dalam pengembangan ilmu pengetahuan dan teknologi sampai saat ini.

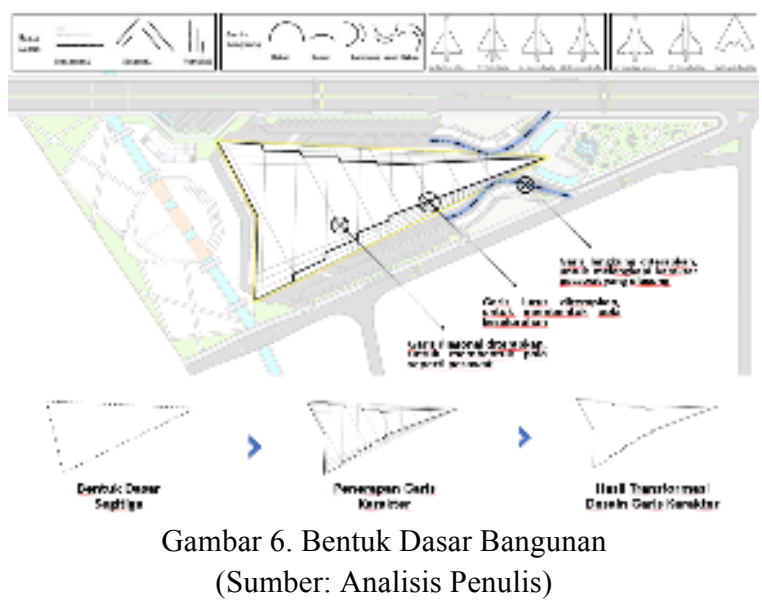

Pada gambar 6 dapat kita lihat pola segitiga diterapkan dengan perpaduan garis karakter sehingga membentuk sebuah tatanan yang kompleks seperti bentuk pesawat. Pesawat sendiri erat kaitannya dengan udara/ angin atau bisa disebut elemen gravitasi, menjadikannya salah satu penghambat pada sistem lalu lintas udara.

Sama halnya dengan pendidikan, jika fasilitas dan rasa malas menjadi sebuah penghambat, bagaimana mungkin kualitas pendidikan khususnya Kota Pekanbaru maupun di Indonesia bisa menjadi lebih baik lagi bahkan mampu bersaing secara global, maka dari itu konsep ini sangatlah erat baik dari segi latar belakang, kebutuhan dan konsep yang digunakan.

c. Analisis gubahan massa bangunan

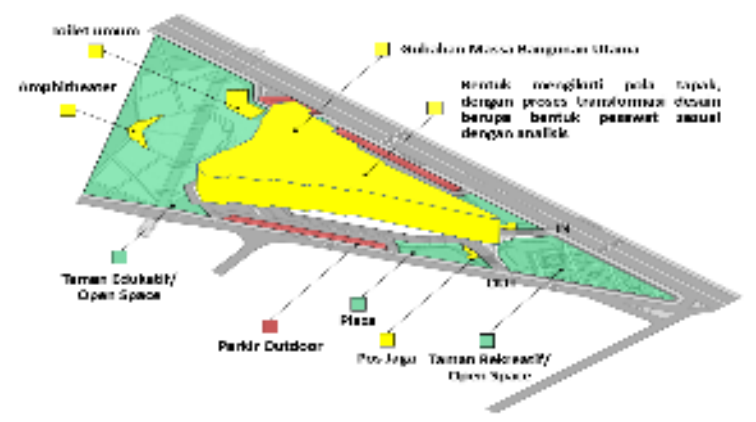

Gambar 7. Bentuk Gubahan Massa Bangunan (Sumber: Analisis Penulis)
Dapat dilihat pada gambar 7, bentuk massa bangunan mengikuti bentuk yang sesuai dengan pola tapak yang berbentuk segitiga. Dengan proses transformasi desain melalui peran garis karakter yang membentuk pola bentukan pesawat, sehingga dapat merespon konsep futuristik yang diusung sesuai dengan yang ingin dicapai.

d. Analisis ruang dalam

Skenario kegiatan menjadi dasar untuk mewujudkan ruang, setiap ruang pameran/ fasilitas lainnya memiliki tingkatan yang dapat disesuaikan dengan kemauan pengunjung terhadap apa yang mereka sukai belajar sambil bermain.

Berikut skenario kegiatan, yang membentuk ruangruang berdasakan kelompok pengunjung :

1) Zona ilmu dasar ( Fase Pengenalan)

2) Zona Science And Technology (Fase Berpikir)

3) Zona Pendukung (Fase Pencernaan)

Dengan pola seperti ini menciptakan ruang dengan kegiatan yang fleksibel dan lebih efisien, pengunjung tidak akan bosan, karena semuanya sejalan dan sesuai dengan proses pemahaman yang mudah dicerna.

e. Analisis sistem sirkulasi dan parkir Sistem sirkulasi terbagi menjadi dua, yaitu sirkulasi horisontal dan sirkulasi vertikal, sebagai berikut :

1) Sirkulasi horisontal :

Pada gambar 8, dapat dilihat sirkulasi horisontal dibagi menjadi tiga, yaitu (Kuning) Massa bangunan utama, (Merah) Parkir Outdoor, dan (Hijau) area vegetasi dan open space. Pola parkir outdoor pola parkir $45^{\circ}$ menghadap jalan.

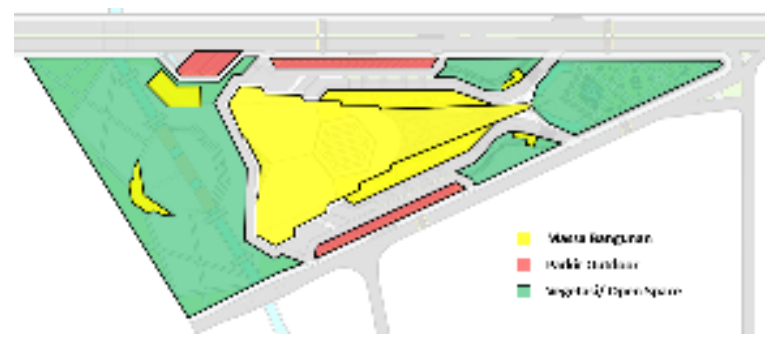

Gambar 8. Analisis Sirkulasi Horisontal (Sumber: Analisis Penulis)

2) Sirkulasi vertikal

Pada gambar 9 dan 10, dapat dilihat sirkulasi vertikal dibagi menjadi empat, yaitu (Biru) Fasilitas umum dan fasilitas peraga sains dan teknologi, (Hijau) Pengelola, (Kuning) area servis, (Merah) area parkir basement. Pola parkir indoor $90^{\circ}$ berhadapan. 


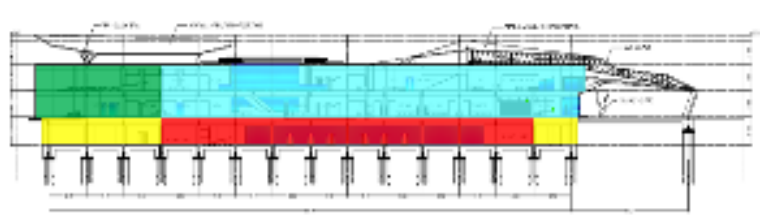

Gambar 9. Analisis Sirkulasi Vertikal Pot. A-A (Sumber: Analisis Penulis)

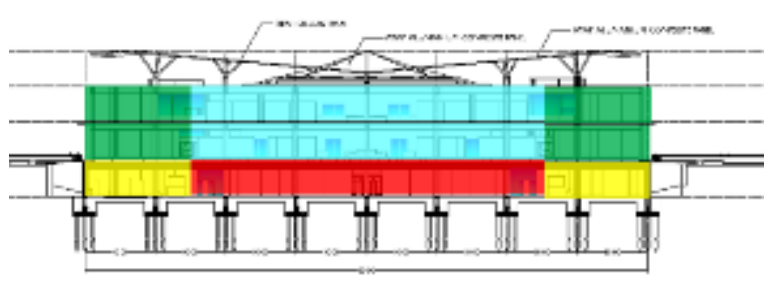

Gambar 10. Analisis Sirkulasi Vertikal Pot. B-B (Sumber: Analisis Penulis)

f. Analisis sistem struktur

Pada gambar 11 dapat dilihat sistem struktur Pekanbaru Science And Technology Center pada bagian struktur bawah menggunakan kombinasi cor beton dan baja. Pada bagian struktur tengah menggunakan struktur yang sama. Dan pada struktur atas menggunakan struktur baja/ space frame.

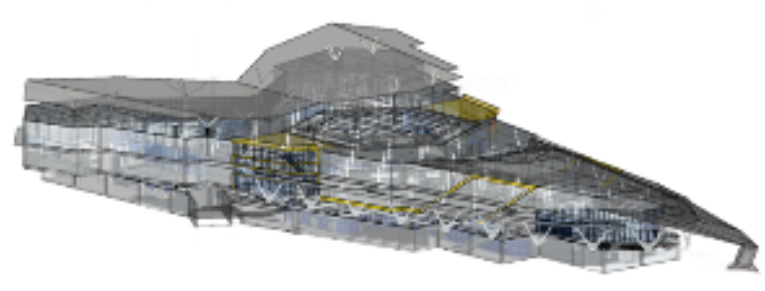

Gambar 11. Analisis Sistem Struktur

(Sumber: Analisis Penulis)

g. Analisis sistem utilitas

Dapat dilihat pada gambar 12, sistem utilitas pada Pekanbaru Science And Technology direncanakan dengan sistem Building Automation System (BAS), dengan penggunaan teknologi otomatisasi, segala aktifitas yang berkaitan utilitas dikontrol langsung oleh satu sistem terpantau dalam Control Room/ Command Center.

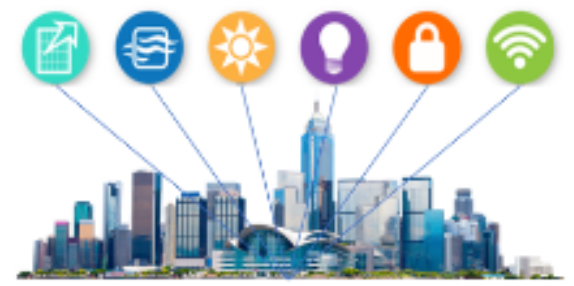

Gambar 12. Building Automation System (BAS) (Sumber: Analisis Penulis)
Baik itu segi pencahayaan, elektrikal, distribusi air bersih dan kotor, keamanan, parkir, dan utilitas lainnya memudahkan kegiatan pengelola, sistem ini merupakan salah satu implementasi penerapan teknologi pada bangunan futuristik. Sehingga berkurangnya aktifitas manusia dalam kegiatan utilitas dapat lebih fokus dalam memberikan pelayanan yang baik terhadap pengunjung.

\section{Konsep Yang Digunakan}

a. Konsep dasar perancangan

Konsep dasar perancangan berpegang pada topik "Pendekatan Arsitektur Futuristik" dengan tema "Pendekatan Rancangan Berbasis Teknologi" untuk mewujudkan tampilan dan karakteristik arsitektur masa depan.

b. Konsep perancangan

Untuk memudahkan perencanaan, diperlukan beberapa konsep terkait penataan lingkungan, arsitektural, ruang dalam, dan penataan gubahan massa, sehingga dapat memenuhi kriteria dari penggunaan topik dan tema yang diterapkan.

c. Konsep perwujudan arsitektur

Konsep perwujudan arsitektur diimplementasikan dalam dua kombinasi yang serasi antara konssep pendidikan dan konsep rekreasi, dimana peran futuristik mampu meberikan ekspektasi yang luar biasa mengundang pengunjung untuk datang dan menikmati apa yang ada didalamnya, dan pengunjung dimanjakan dengan perpaduan teknologi yang disuguhkan.

Sehingga jelas tujuan daripada topik dan tema sangat erat kaitannya, selain penikmatan arsitektur tetapi juga bermanfaat pengaplikasiannya. seperti pada gambar 13 dapat dilihat hasil akhir dari proses transformasi bentuk melalui penerapan garis karakter sampai membentuk pola yang dinamis dan atraktif.

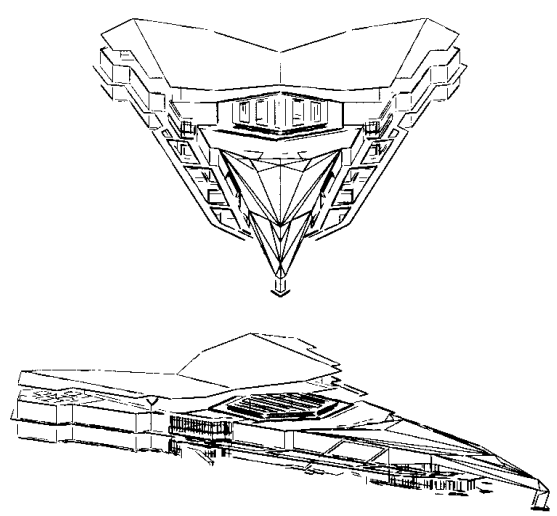

Gambar 13. Konsep Perwujudan Arsitektur (Sumber: Konsep Penulis) 


\section{HASIL DESAIN 3D ANIMASI :}

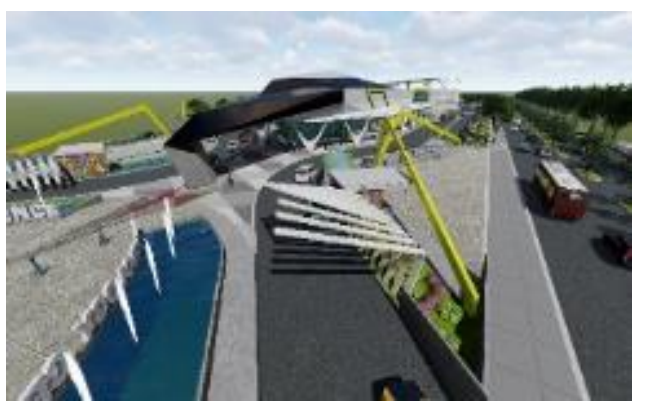

a. view gate masuk utama

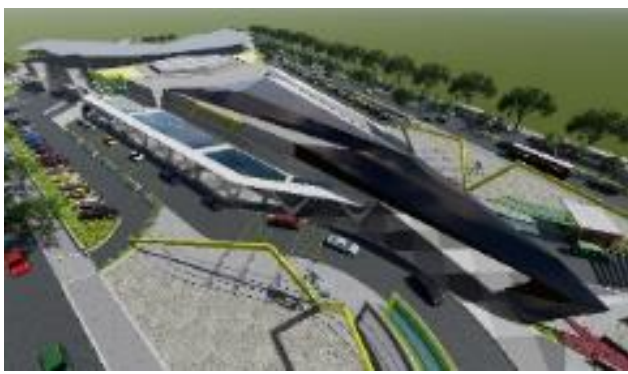

b. view tampak perspektif

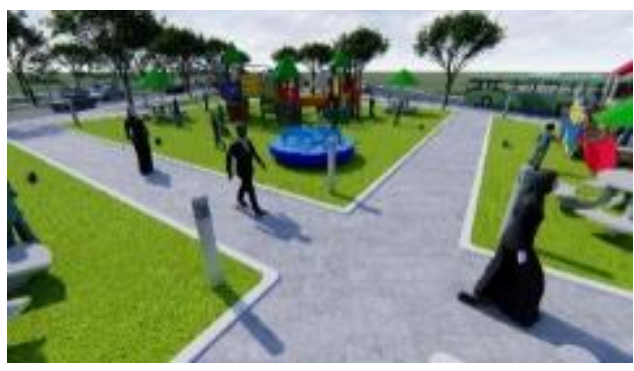

c. view taman rekreatif

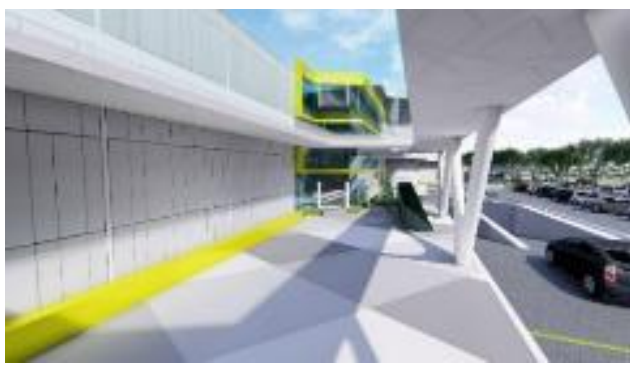

d. view taman rekreatif

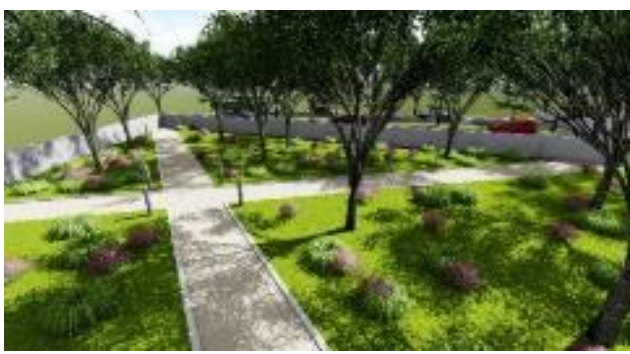

e. view taman rekreatif

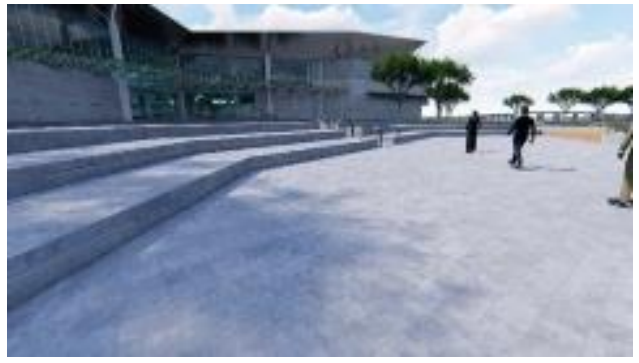

f. view tampak belakang

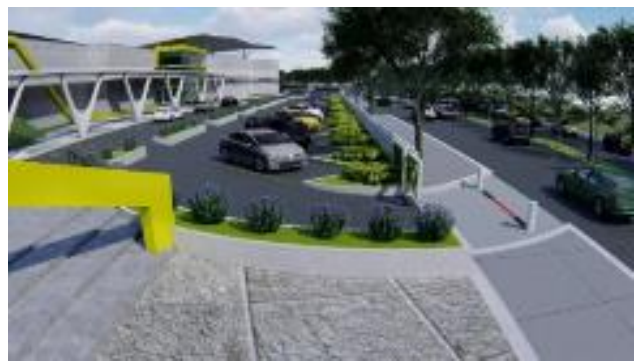

g. view parkir outdoor

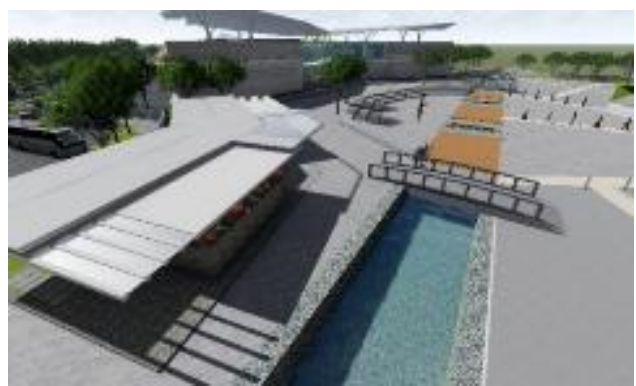

h. view area outdoor bagian belakang

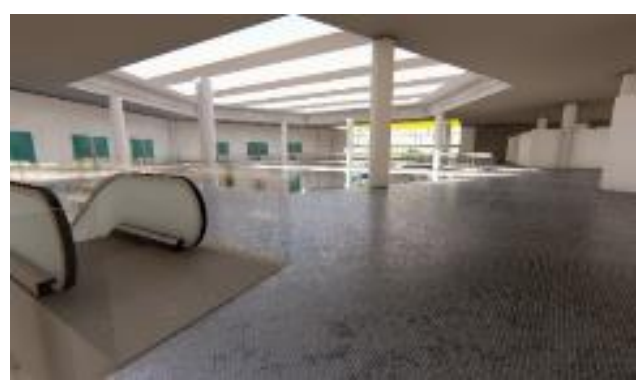

i. view skylight pada area void lt.2

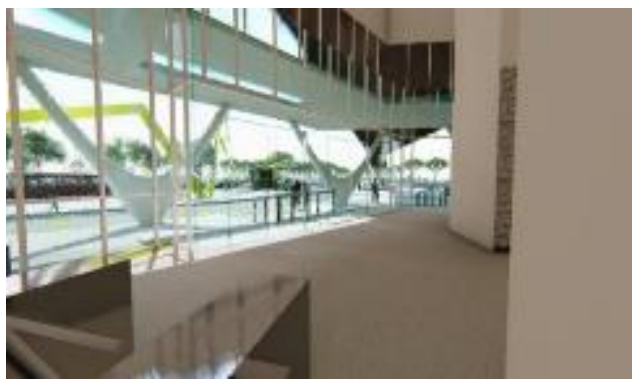

b. view lobby sisi bagian kiri 


\section{KESIMPULAN}

Kesimpulan dari penelitian "Pekanbaru Science And Technology Center" ini menghasilkan planning programing dan konsep dasar rancangan yang selanjutnya di desain dalam bentuk Pekanbaru Science And Technology Center sesuai dengan perencanaannya.

Science And Technology Center di Kota Pekanbaru ini dirancang dengan konsep "Pendekatan Arsitektur Futuristik" dengan tema "Pendekatan Rancangan Berbasis Teknologi". Terletak di Jln. Tuanku Tambusai 2, Kecamatan Payung Sekaki, Kelurahan Air Hitam, Pekanbaru-Riau, Indonesia.

Besar harapan dalam perencanaan "Pekanbaru Science And Technology Center" ini adalah fasilitas pembelajaran non-formal yang tujuannya adalah untuk meningkatkan kualitas pendidikan khususnya di Kota Pekanbaru agar lebih baik lagi, serta mampu melahirkan sumber daya manusia yang dapat bersaing baik secara nasional, hingga ke level internasional.

Berdasarkan data dan berita yang ada, dengan akan diresmikannya Science And Technology Center di Kota Pekanbaru, saran untuk pemerintah Kota Pekanbaru dapat membuat fasilitas pembelajaran non-formal seperti Science And Technology Center dengan selayak dan sebaik mungkin, karena dampaknya akan sangat besar apabila diwujudkan, mengingat Kota Pekanbaru tidak banyak area wisata yang dapat dikunjungi, bukan tidak mungkin jika dibangun Science And Technology Center bisa menjadi percontohan Kota Pendidikan yang Go-Internasional.

Dan adapun saran untuk peneliti selanjutnya yaitu agar dapat memperdalam dan memamahami, bahwa fasilitas seperti Science And Technology Center atau bisa disebut IPTEK, bukan hanya semata-mata mempalajari ilmu melalui alat peraga, media visual, dan teknologi lainnya. Tetapi bagaimana kita berpikir bahwa dimulai dari sanalah, sumber daya manusia yang berkualitas bisa bersaing agar kita tidak ketinggalan dan bersaing dengan negara-negera lain.

\section{DAFTAR PUSTAKA}

Data Buku :

Sant'Elia, Antonia. 2009. Architecture Futuristic. Futurism An Anthology

Davies, Colin. 1988. High Tech Architecture. London: Themes and Hudson

Foster, Norman. 1980. High Tech Architecture. Norman Foster Buildings.

Neufert, Ernst. 1994. Data Arsitek Edisi Kedua, Jilid 1 dan 2. Jakarta: Erlangga.

G.Z, Brown, 1987, Buku Sumber Konsep, Intermatra, Bandung.

Ching Francis D.K, 2008, Arsitektur Bentuk, Ruang,

dan Tatanan, Erlangga
ICOM 1974s, Section II Definitions, Article 3-4, adopted by the 11st General Assembly. Copenhagen, Denmark, 14 June 1974

Data Jurnal, Skripsi dan Website :

Kemenristek. 2001. Keputusan Menteri No. 75/M/Kp/IX/2001 https://ristekdikti.go.id

Dirjenpp. 2017. Peraturan Presiden Tentang Pusat Science No. 106. http://ditjenpp.kemenkumham.go.id/database -peraturan/peraturan-presiden.html

Pekanbaru. 2018. Visi dan Misi Kota Pekanbaru https://www.riau.go.id/home/content/858/vis i-dan-misi

Tifanny, 2012. Medan Science And Technology Centre.http://repository.usu.ac.id/bitstream/h andle/123456789/37179/Cover.pdf? sequence $=6 \&$ is Allowed $=y$

Rahayu, Agus. 2014. Arsitektur Futuristik. http://rumahwaskita.com/artikel/arsitekturfuturistik/?lang=en

Satriawan, Yudha. 2019. Biografi BJ Habibie. https:/www.voaindonesia.com/a/sutantodosen-uns-sang-penulis-buku-biografi-bjhabibi-/5083435.html 